\title{
Antimicrobial Activity of Ag/Ag2O Nanoparticles Synthesized by Dead Biomass of Yeast and their Biocompatibility with Mammalian Cell Lines
}

\author{
Marcia Regina Salvadori*, Telma Alves Monezi, Dolores Ursula Mehnert, Benedito Corrêa \\ Department of Microbiology, Institute of Biomedical Sciences II, University of São Paulo, São Paulo, Brazil \\ *Corresponding Author: Marcia Regina Salvadori, Department of Microbiology, Institute of \\ Biomedical Sciences II, University of São Paulo, São Paulo, Brazil
}

\begin{abstract}
The high frequency of resistance of pathogenic bacteria and fungi to commercial antimicrobial agents has become an alarming public health threat. We report a versatile option for antimicrobial therapy, through recycling metal pollutants, using Ag/Ag2O nanoparticles (NPs) naturally synthesized by dead biomass of the yeast Rhodotorula mucilaginosa ( $R$. mucilaginosa), a nano-biosorbent isolated from the wastewater of a mine in the Amazon region. In in vitro assays, the Ag/Ag2O NPs exhibited promissing antimicrobial activity against Gram-positive Methicillin-resistant Staphylococcus aureus (MRSA) and Gramnegative multidrug-resistant (MDR) Escherichia coli (E. coli) strains, and against the yeast Cryptococcus neoformans (C. neoformans), as demonstrated by the disc diffusion method, minimum inhibitory concentration (MIC), minimal bactericide concentration $(M B C)$ and minimum fungicidal concentration $(M F C)$. The atomic force microscopy (AFM) revealed complete destruction of the microorganisms by the Ag/Ag2O NPs. The toxicity assays of the Ag/Ag2O NPs in mammalian cells demonstrated reduced cytotoxicity, an important characteristic in biomedical application. The Ag/Ag2O NPs synthesized by the nanobiosorbent $R$. mucilaginosa exerts a potent inhibitory effect on microorganisms and is safe for eukaryotic cells, providing a possible application to nanomedicine and, at the same time, recycling polluting material.
\end{abstract}

Keywords: Silver nanoparticles, dead biomass, bacteria, yeast, antimicrobial activity, mammalian cell lines, wastewater, mine.

\section{INTRODUCTION}

Outbreaks of infectious diseases caused by different pathogenic bacteria and fungi and the development of antimicrobial resistance have led to the search for new antimicrobial agentes [1]. A literature review demonstrated remarkable bactericidal, fungicidal and antiviral activity of silver NPs [2]. The chemical and physical methods currently used for the synthesis of NPs are expensive, require high temperatures and high pressures, and produce hazardous wastes that posses risk to the environment [3]. In this respect, biological methods for the nanomaterials synthesis are used worldwide to create nano-factories [4], particularly for the preparation of silver NPs that offer several benefits such as compatibility for pharmaceutical and biomedical application [5]. Yeasts have become important in nanotechnology as producers of NPs, due to their advantages such as low-cost, rapid growth and easy preparation and biomass handling. Salvadori et al. [6] described for the first time the efficient and low-cost synthesis of $\mathrm{Ag} / \mathrm{Ag}_{2} \mathrm{O}$ NPs using dead biomass of the yeast $R$. mucilaginosa, isolated from the weastewater of a mine in the Amazon region, for nanobioremediation of silver waste and its reuse in NPs form.

The MRSA are important pathogenic Gram-positive bacteria in the healthcare setting that continue to persist in the hospital and community. In humans, S. aureus causes central nervous system infections, invasive endocarditis, urinary tract infections, superficial skin lesions and localized abscesses, osteomyelitis, septicemia, septic arthritis, and pneumonia [7]. More than half of all infections in vascular surgery are caused by MRSA [8].

Resistance to three or more antimicrobial agents in the absence of intrinsic resistance is defined as multidrug resistance. The MDR among clinical isolates of bacteria such as E. coli, is an important healthcare problem and is associated with a global increase in morbidity and mortality [9]. 
The encapsulated saprophytic yeast, C. neoformans var grubii (capsular serotype D) causes $82 \%$ of cryptococcal diseases in the world [10]. Var. neoformans (capsular serotype A) accounts for 20\%$30 \%$ of HIV-associated cryptococcal meningitis in northern Europe [11]. Decaying organic matter, soil and avian guano are the main environmental reservoirs of both subtypes of $C$. neoformans [10].

The antimicrobial potential of silver NPs is due to the strong oxidative activity of their surface and the release of silver ions into biological environments. An important advantage of biogenic NPs is that they are less cytotoxic than commercial silver NPs or silver ions [12].

In a previous study, we reported for the first time the use of dead biomass of the yeast $R$. mucilaginosa isolated from a mine in Amazon region for nanobioremediation and intracellular synthesis of metallic copper NPs [13]. The same system was used for the nanobioremediation and production of magnetic Ni/NiO NPs in the form of nanostructured films [14] and, recently, with metal silver [6]. In the present study, we explore for the first time effectiveness of $\mathrm{Ag} / \mathrm{Ag}_{2} \mathrm{O} \mathrm{NPs}$, synthesized by the nanobioremediator (dead biomass of yeast $R$. mucilaginosa) [6], as an antibacterial and antifungal against representative microorganisms of public health concern. The safety of these NPs was demonstrated by their low cytotoxicity in mammalian cells, increasing the choice of lowcost, safe and effective antimicrobials.

\section{MATERIALS AND MeTHODS}

\subsection{Biosynthesis of Biogenic $\mathrm{Ag} / \mathrm{Ag}_{2} \mathrm{O} \mathrm{Nps}$}

R. mucilaginosa was isolated from water collected in a copper waste pond of the Sossego mine, which belongs to the Company Vale S.A. located in Canaã dos Carajás, Pará, Brazilian Amazonia region $\left(0^{\circ} 26^{\prime} \mathrm{S}\right.$ latitude and $50^{\circ} 4^{\prime} \mathrm{W}$ longitude) [13]. Biosynthesis of the $\mathrm{Ag} / \mathrm{Ag}_{2} \mathrm{O}$ NPs by the yeast was performed according to Salvadori et al [6].

\subsection{Bacterial Strains}

The Gram-positive Staphylococcus aureus MRSA ST5 and Gram-negative Escherichia coli BL-II-11 (MDR) strains, were obtained from the Bacterial Culture Collection of the Bacteriology Section of the Departament of Microbiology, Institute of Biomedical (ICB), University of São Paulo. For all experiments, the strains were cultured in Mueller-Hinton (MH) medium.

\subsubsection{Determination of the Antibacterial Activity of $\mathrm{Ag} / \mathrm{Ag}_{2} \mathrm{O}$ Nps By the Disc Diffusion Method}

The antibacterial activity of the $\mathrm{Ag} / \mathrm{Ag}_{2} \mathrm{O}$ NPs was evaluated by the diffusion disc method commonly used for antibiotics. The bacterial strains were inoculated $\left(10^{8} \mathrm{CFU} \mathrm{mL} \mathrm{m}^{-1}\right)$ into plates with $\mathrm{MH}$ agar (Oxoid, England) and paper discs (5 mm in diameter) instilled with different concentrations $(1,2,5$, $10,20,50,70$ and $100 \mu \mathrm{g} \mathrm{mL}^{-1}$ ) of $\mathrm{Ag} / \mathrm{Ag}_{2} \mathrm{O}$ NPs were laid on the inoculated test microorganism. The plates were incubated at temperature of $37^{\circ} \mathrm{C}$ during $24 \mathrm{~h}$. Antimicrobial activity was determined by measuring the inhibition zone around the disc.

\subsubsection{Determination of the Antibacterial Effectiveness of Ag/Ag2O NPs by the MIC Assay}

The antibacterial activity of the $\mathrm{Ag} / \mathrm{Ag} 2 \mathrm{O}$ NPs was evaluated based on the minimum inhibitory concentration (MIC), using the standard broth tube dilution method [15]. The MIC was determined against a bacterial concentration of $106 \mathrm{CFU}$ mL-1 cultured in MH broth (Oxoid, England) with different concentrations of $\mathrm{Ag} / \mathrm{Ag} 2 \mathrm{O}$ NPs $(1,2,5,10,20,50,70$ and $100 \mu \mathrm{g} \mathrm{mL}-1)$. The cultures were incubated at $37^{\circ} \mathrm{C}$, during $24 \mathrm{~h}$ at $250 \mathrm{rpm}$. The bacterial concentrations were determined by measuring optical density (OD) at $600 \mathrm{~nm}$. The MIC was defined as the lowest concentration of NPs that inhibited bacterial growth.

\subsubsection{Determination of the Antibacterial Activity of $A g / A g 2 O$ NPs by the MBC Assay}

The minimum bactericidal concentration (MBC) of the Ag/Ag2O NPs was determined using the same solutions as in the tube dilution test of the MIC assay [16], which were inoculated into MH agar plates at $37^{\circ} \mathrm{C}$ for $24 \mathrm{~h}$. The bactericidal effect of different $\mathrm{Ag} / \mathrm{Ag} 2 \mathrm{O}$ NPs concentrations was evaluated by the absence of colonies on the agar plate. The MBC was defined as the lowest concentration of $\mathrm{Ag} / \mathrm{Ag} 2 \mathrm{O}$ NPs that totally inhibited bacterial growth when compared to the positive control (no treatment with $\mathrm{Ag} / \mathrm{Ag} 2 \mathrm{O} \mathrm{NPs}$ ). 


\subsection{Yeast Strain}

The yeast Cryptococcus neoformans H-99, was obtained from the Fungal Culture Collection of the Micology Section of the Departament of Microbiology, ICB, University of São Paulo. For all experiments, the strain was cultured in Sabouraud Dextrose (SD) medium.

\subsubsection{Determination of Antifungal Activity of Ag/Ag2O NPs by the Disc Diffusion Method}

The disc diffusion method was used to evaluate the in vitro antifungal activity of $\mathrm{Ag} / \mathrm{Ag} 2 \mathrm{O}$ NPs against C. neoformans. Petri dishes containing Sabouraud Dextrose Agar (SDA) (Oxoid, England) were inoculated with the fungal strain (106 CFU mL-1) and paper discs $(5 \mathrm{~mm}$ in diameter) instilled with different concentrations $(0.1,0.15,0.2,0.5,1,2,5,10,20$, and $40 \mu \mathrm{g} \mathrm{mL}-1)$ of Ag/Ag2O NPs were laid on the inoculated test microorganism. The plates were incubated at temperature of $35^{\circ} \mathrm{C}$ during $48 \mathrm{~h}$ and antimicrobial activity was determined by measuring the inhibition zone around the disc.

\subsubsection{Determination of the Antifungal Activity of Ag/Ag2O NPs by the MIC Assay}

The antifungal activity of the $\mathrm{Ag} / \mathrm{Ag} 2 \mathrm{O}$ NPs was also evaluated based on the MIC, using the standard broth tube dilution method [15]. The MIC was determined against a fungal concentration of $106 \mathrm{CFU}$ mL-1 cultured in Sabouraud Dextrose Broth (SDB) (Oxoid, England) with different concentrations of $\mathrm{Ag} / \mathrm{Ag} 2 \mathrm{O}$ NPs $(0.1,0.15,0.2,0.5,1,2,5,10,20$, and $40 \mu \mathrm{g} \mathrm{mL}-1)$. The cultures were incubated at $35^{\circ} \mathrm{C}$, during $48 \mathrm{~h}$ at $250 \mathrm{rpm}$. The fungal concentrations were determined by measuring optical density (OD) at $600 \mathrm{~nm}$. The MIC was defined as the lowest concentration of NPs that inhibited the growth of the yeast.

\subsubsection{Determination of the Antifungal Activity of Ag/Ag2O NPs by the MFC Assay}

The minimum fungicidal concentration (MFC) of the Ag/Ag2O NPs was determined using the same solutions as in the dilution test of the MIC assay [16], which were inoculated into SDA plates at $35^{\circ} \mathrm{C}$ for $48 \mathrm{~h}$. The fungicidal effect of different $\mathrm{Ag} / \mathrm{Ag} 2 \mathrm{O}$ NPs concentrations was evaluated by the absence of colonies on the agar plate. The MFC was defined as the lowest concentration of $\mathrm{Ag} / \mathrm{Ag} 2 \mathrm{O}$ NPs that totally inhibited fungal growth when compared to the positive control (no treatment with $\mathrm{Ag} / \mathrm{Ag} 2 \mathrm{O}$ NPs).

\subsection{Atomic Force Microscopy of Bacterial and Yeast Cells After Treatment with Ag/Ag2O Nps}

Changes in untreated bacterial and yeast cells and cells treated with $\mathrm{Ag} / \mathrm{Ag} 2 \mathrm{O}$ NPs were investigated by Atomic-force microscopy (AFM). Samples were scanned with an AFM Icon Nanoscope V (Bruker) using Tapping mode AFM technique with oscillating cantilever to scan the sample surface with scan rate of $1 \mathrm{~Hz}$ and a silicon nitride tip with resonance frequency of about $250 \mathrm{kHz}$.

\subsection{Cytotoxicity Assays with Ag/Ag2O Nps}

BeWo cells (human placental choriocarcinoma), A-253 cells (human submaxillary salivary gland), KNS-42 cells (human glioma) and Vero cells (african green monkey kidney) were obtained from the Laboratory of Human and Animals Enteric Viruses, Department of Microbiology, ICB, University of São Paulo. The KNS-42 and Vero cells were cultured at $37^{\circ} \mathrm{C}$ in Dulbecco's Modified Eagle Mediumhigh glucose (DMEM) (Sigma-Aldrich, St. Louis, MO, USA), supplemented with $10 \%$ fetal bovine serum (FBS) (Sigma-Aldrich, St. Louis, MO, USA). A-253) and BeWo cells were cultured in McCoy medium (Sigma-Aldrich, St. Louis, MO, USA) and F-12K medium (Sigma-Aldrich, St. Louis, MO, USA), repectively, under the same conditions as described for the other cells. For the evaluation of cytotoxic activity [17], $100 \mu \mathrm{L}$ medium and $1.5 \times 105$ cells per well were added to the wells of 96-well plastic plates. After $24 \mathrm{~h}$, culture medium was aspirated and $100 \mu \mathrm{L}$ of fresh medium specific for each cells without FBS and different concentrations of Ag/Ag2O NPs were added to each well. The plates were incubated at $37^{\circ} \mathrm{C}$ in a $5 \% \mathrm{CO} 2$ atmosphere. Morphological changes were observed over a period of $48 \mathrm{~h}$. Untreated cells were used as positive control. Cell viability was evaluated by the Alamar Blue (AB) assay (Thermo Fisher Scientific, Waltham, MA, USA), which assesses cell viability based on the reduction potential of metabolically active cells. Briefly, following the $48 \mathrm{~h}$ incubation, $10 \mu \mathrm{l}$ of $\mathrm{AB}$ solution was added to each well. After $4 \mathrm{~h}$ incubation at $37^{\circ} \mathrm{C}$, the optical density was then measured at the excitation and emission wavelengths of 570 and $600 \mathrm{~nm}$, respectively, and the results were read using a fluorescence spectrophotometer (GloMax®-Multi Detection System - Promega Corporation). 
Antimicrobial Activity of Ag/Ag2O Nanoparticles Synthesized by Dead Biomass of Yeast and their Biocompatibility with Mammalian Cell Lines

\section{RESULTS AND DISCUSSION}

The present study used a synthetic biological system consisting of dead biomass of the yeast $\mathrm{R}$. mucilaginosa as a nano factory to synthesize an antimicrobial $\mathrm{Ag} / \mathrm{Ag} 2 \mathrm{O}$ NPs. Initially this synthetic biological system (dead biomass of the R. mucilaginosa) become a natural tool to performing functions for cleaning environmental as metals nanobiosorbent from wastewater $[6,13,14]$, and synthesise concomitantly in NPs with high aggregated comercial value $[6,13,14]$. And now as the principal focus of the present study, we use these Ag/Ag2O NPs with a spherical shape and average size of $11 \mathrm{~nm}$ as an antimicrobial against bacteria and fungi and analysed their cytotoxicity in mammalian cells.

\subsection{Antimicrobial Activity of Ag/Ag2O Nps}

Silver NPs widely recognized for their antimicrobial activity [18]. In this respect, Ag/Ag2O NPs synthesized by dead yeast biomass may be a novel choice of agents for antimicrobial therapy, showing promising results in both bacteria and yeast.

E. coli MDR and MRSA were challenged with Ag/Ag2O NPs concentrations of 1 to $100 \mu \mathrm{g} / \mathrm{ml}$. Both E. coli MDR and MRSA were inhibited by a concentration over $1 \mu \mathrm{g} / \mathrm{ml}$, in the disc diffusion test (Fig. 1). Table 1 shows the diameter of the inhibition zones at the different concentrations of $\mathrm{Ag} / \mathrm{Ag} 2 \mathrm{O}$ NPs. The bacteriostatic effect of Ag/Ag2O NPs was evaluated based on their MIC, which was the same for both bacterial species (Table 2). The decrease in absorbance observed at a concentration of NPs higher than $1 \mu \mathrm{g} / \mathrm{ml}$, suggests that cell death occurred in the stationary phase. Analysis of the number of colonies formed on the MH agar plates showed bactericidal effect of the NPs was dose dependent in all assays, and no bacterial growth of either species was observed at NPs concentrations higher than $1 \mu \mathrm{g} / \mathrm{ml}$ in the MBC assays. The $\mathrm{Ag} / \mathrm{Ag} 2 \mathrm{O}$ NPs exhibited a high antibacterial activity for both bacteria when compared with results already described in the literature for antibiotics commercially available and also metal NPs of the biogenic origin [12,19].
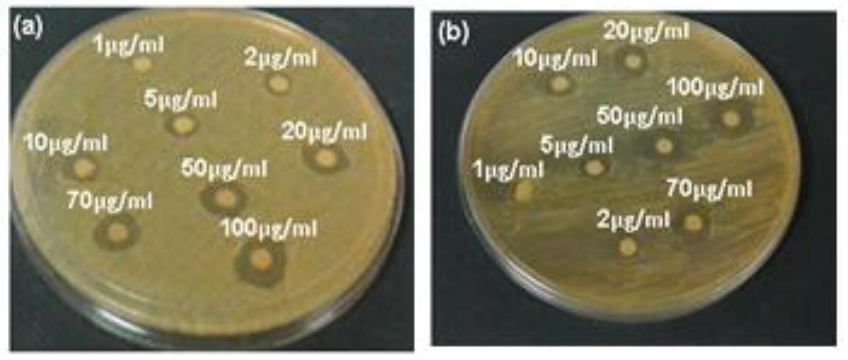

Figure1. Antibacterial activity of Ag/Ag2O NPs against against E. coli MDR (a) and MRSA (b) determined by the disc diffusion method.

Table1. Inhibitory activity from disc diffusion method of Ag/Ag2O NPs against E. coli MDR and MRSA.

\begin{tabular}{|c|c|c|}
\hline Bacteria & $\begin{array}{c}\text { Ag/Ag } \mathbf{O} \mathbf{N P s} \\
\text { Concentrations }(\boldsymbol{\mu g} / \mathbf{m l})\end{array}$ & Inhibition zone (mm) \\
\hline E. coli MDR & 1 & Resistant \\
\hline & 2 & 11 \\
\hline & 5 & 12 \\
\hline & 10 & 14 \\
\hline & 20 & 17 \\
\hline & 50 & 18 \\
\hline & 70 & 20 \\
\hline & 100 & Resistant \\
\hline & 1 & 11 \\
\hline & 2 & 13 \\
\hline & 5 & 15 \\
\hline & 10 & 17 \\
\hline & 20 & 19 \\
\hline & 50 & 20 \\
\hline & 70 & 22 \\
\hline
\end{tabular}


Antimicrobial Activity of Ag/Ag2O Nanoparticles Synthesized by Dead Biomass of Yeast and their Biocompatibility with Mammalian Cell Lines

Table2. MIC of Ag/Ag2O NPs against E. coli MDR and MRSA.

\begin{tabular}{|c|c|c|}
\hline Bacteria & $\begin{array}{c}\mathrm{Ag} / \mathrm{Ag}_{2} \mathrm{O} \mathrm{NPs} \\
\text { Concentrations }(\mu \mathrm{g} / \mathrm{ml}) \\
\end{array}$ & Absorbance (OD 600nm) \\
\hline \multirow[t]{9}{*}{ E. coli MDR } & Control (without NPs) & 2.3 \\
\hline & 1 & 1.4 \\
\hline & 2 & 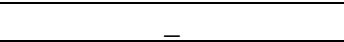 \\
\hline & 5 & - \\
\hline & 10 & $=$ \\
\hline & 20 & $=$ \\
\hline & 50 & - \\
\hline & 70 & - \\
\hline & 100 & $=$ \\
\hline \multirow[t]{9}{*}{ MRSA } & Control (without NPs) & 1.1 \\
\hline & 1 & 0.5 \\
\hline & 2 & 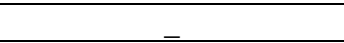 \\
\hline & 5 & _ \\
\hline & 10 & - \\
\hline & 20 & - \\
\hline & 50 & \\
\hline & 70 & 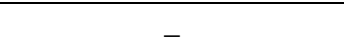 \\
\hline & 100 & \\
\hline
\end{tabular}

The Figures 2 and 3 illustrate the results of AFM analysis of the effect of Ag/Ag2O NPs on MRSA and E. coli MDR, respectively, demonstrating damages to the cells of both bacterial species compared to untreated cells (control). The results of AFM analysis of bacterial cells treated with biogenic silver NPs are relatively recent. The mechanism underlying the inhibitory effect of silver NPs on microorganisms has not been fully elucidated. Studies suggest a direct interaction of silver NPs with the cell membrane, promoting its disruption [20]. Furthermore, an interaction of silver NPs with thiol (-SH) groups found in proteins has been proposed, as well as the production of reactive oxigen species (ROS) [21] or release of silver ions inhibiting respiratory enzymes, also generating ROS [22] Another study suggested that thiol groups present in prokaryotic cells form complexes with silver NPs, causing the death of these cells [23].
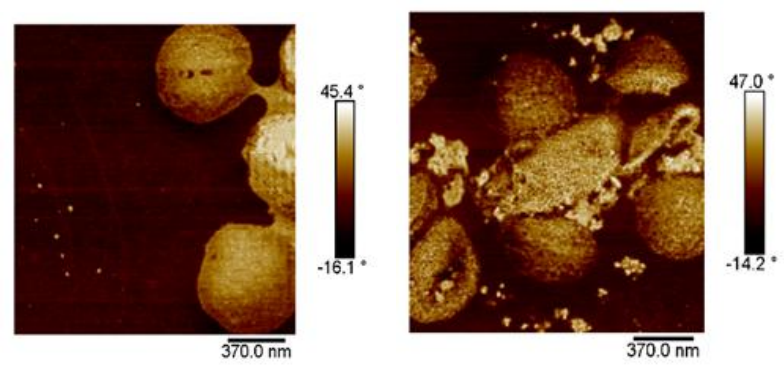

Figure2. AFM images illustrating the antimicrobial activity of Ag/Ag2O NPs against MRSA. (a) Image of MRSA control and (b) Image of MRSA cells damaged after treatment with Ag/Ag2O NPs.
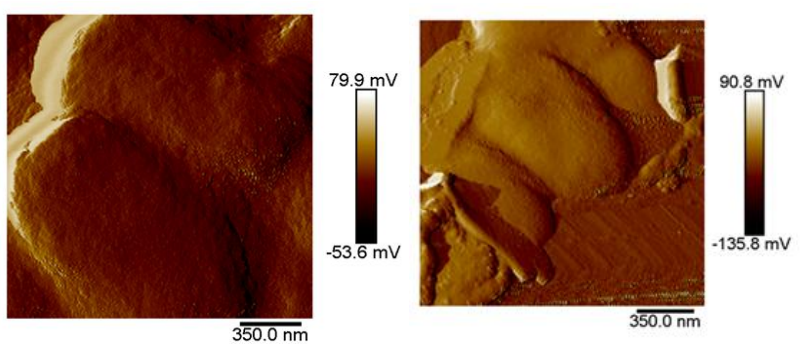

Figure3. AFM images illustrating the antimicrobial activity of Ag/Ag2O NPs against E. coli MDR. (a) Image of E. coli MDR control and (b) Image of E. coli MDR cells damaged after treatment with Ag/Ag2O NPs.

Concentrations of the Ag/Ag2O NPs of 0.1 to $40 \mu \mathrm{g} / \mathrm{ml}$ were tested by the disc diffusion method and potente antifungal activity against the yeast $\mathrm{C}$. neoformans was observed at a concentration higher than $0.15 \mu \mathrm{g} / \mathrm{ml}$ (Fig. 4). Table 3 shows the diameter of the inhibition zones at the different $\mathrm{Ag} / \mathrm{Ag} 2 \mathrm{O}$ NPs concentrations, and the results were confirmed by the MIC (Table 4) and MFC. The Ag/Ag2O NPs exhibited a high efficacy as antifungal against an important pathogen, the yeast $\mathrm{C}$. neoformans compared with other biogenic silver NPs [24]. 
Antimicrobial Activity of Ag/Ag2O Nanoparticles Synthesized by Dead Biomass of Yeast and their Biocompatibility with Mammalian Cell Lines
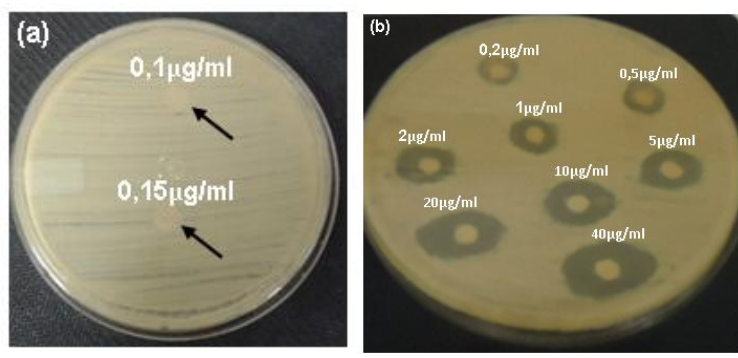

Figure4. Antifungal activity of Ag/Ag2O NPs against C. neoformans determined by the disc diffusion methods. (a) C. neoformans resistante to discs impregnated with Ag/Ag2O NPs at concentrations of 0.1 to $0.15 \mu \mathrm{g} / \mathrm{ml}$ (black arrows). (b) C. neoformans susceptible to Ag/Ag2O NPs at concentrations of 0.2 to $40 \mu \mathrm{g} / \mathrm{ml}$.

Table3. Inhibitory activity from disc diffusion method of Ag/Ag2O NPs against $C$. neoformans

\begin{tabular}{|c|c|c|}
\hline Yeast & $\begin{array}{c}\text { Ag/Ag } \mathbf{O} \mathbf{O} \text { NPs } \\
\text { Concentrations }(\boldsymbol{\mu g} / \mathbf{m l})\end{array}$ & Inhibition zone (mm) \\
\hline C. neoformans & 0.1 & Resistant \\
\hline & 0.15 & Resistant \\
\hline & 0.2 & 16 \\
\hline & 0.5 & 20 \\
\hline & 1 & 22 \\
\hline & 2 & 25 \\
\hline & 5 & 27 \\
\hline & 10 & 29 \\
\hline & 20 & 31 \\
\hline
\end{tabular}

Table4. MIC of Ag/Ag2O NPs against C. neoformans.

\begin{tabular}{|c|c|c|}
\hline Yeast & $\begin{array}{c}\mathbf{A g} / \mathbf{A g}_{2} \mathbf{O} \mathbf{~ N P s} \\
\text { Concentrations }(\boldsymbol{\mu g} / \mathbf{m l})\end{array}$ & Absorbance (OD 600nm) \\
\hline C. neoformans & Control (without NPs) & 1.8 \\
\hline & 0.1 & 1.3 \\
\hline & 0.15 & 1.3 \\
\hline & 0.2 & - \\
\hline & 0.5 & - \\
\hline & 1 & \\
\hline & 2 & \\
\hline & 5 & \\
\hline & 10 & \\
\hline
\end{tabular}

The Figure 5 shows the AFM images illustrating the effect of Ag/Ag2O NPs on the yeast C. neoformans. Damaged yeast cells can be observed when compared to untreated cells (control). A recente study proposed that silver NPs exert antifungal effects through apoptosis [25], but the exact mechanism underlying the inhibitory effects of silver ions on yeasts remains to be elucidated.
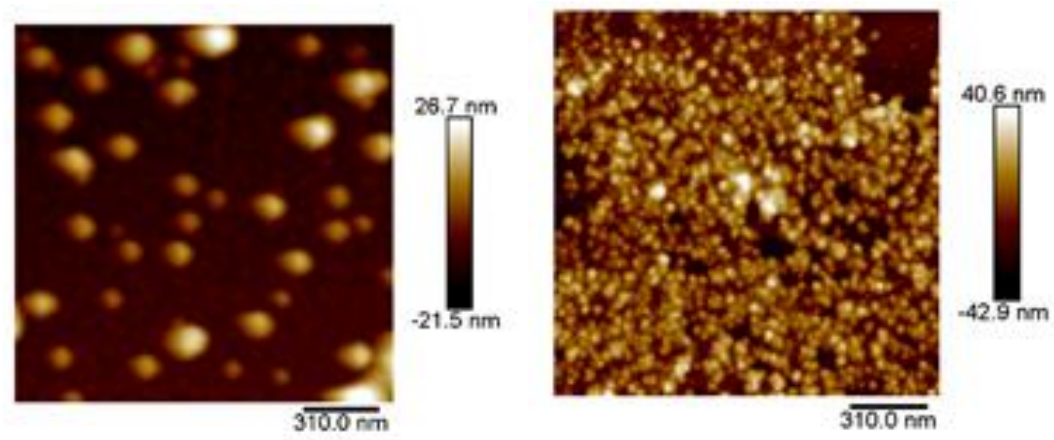

Figure5. AFM images illustrating the antimicrobial activity of Ag/Ag2O NPs against C. neoformans. (a) Image of $C$. neoformans control and (b) Image of C. neoformans cells damaged after treatment with Ag/Ag2O NPs.

International Journal of Research Studies in Microbiology and Biotechnology (IJRSMB) $\quad$ Page | 12 


\subsection{Effect of Ag/Ag2O Nps on Mammalian Cells}

To further elucidate the effect of Ag/Ag2O NPs on eukaryotic cells, mammalian cells were placed in contact with different concentrations of NPs. The cells were analysed by inverted light microscope and by the $\mathrm{AB}$ assay (Fig. 6). Microscope imaging suggests that $\mathrm{Ag} / \mathrm{Ag} 2 \mathrm{O}$ NPs do not significantly affect mammalian cells. This was confirmed by the $\mathrm{AB}$ assay, especially when the cells were exposed to a low dose yet higher than the dose necessary to achieve antimicrobial activity. The $A B$ assays revealed that BeWo and A-253 cells (human origin) are significantly resistant when treated with high concentrations of Ag/Ag2O NPs, with an approximate IC50 value of $150 \mu \mathrm{g} / \mathrm{ml}$ (Fig. 6a and b). KNS42 cells, also of human origin (neuronal cells), and Vero cells were also resistant to Ag/Ag2O NPs with approximate IC50 values of 70 and $60 \mu \mathrm{g} / \mathrm{ml}$ respectively (Fig. 6c and d). The IC50 values found in our study were similar to or higher than those reported in the literature for silver NPs $[12,26]$.

(a)
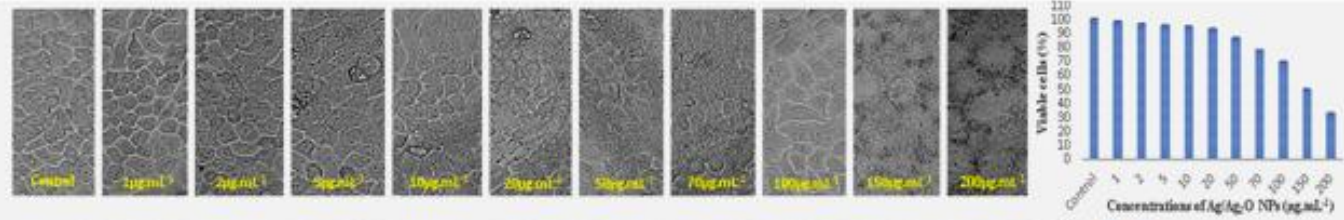

(b)
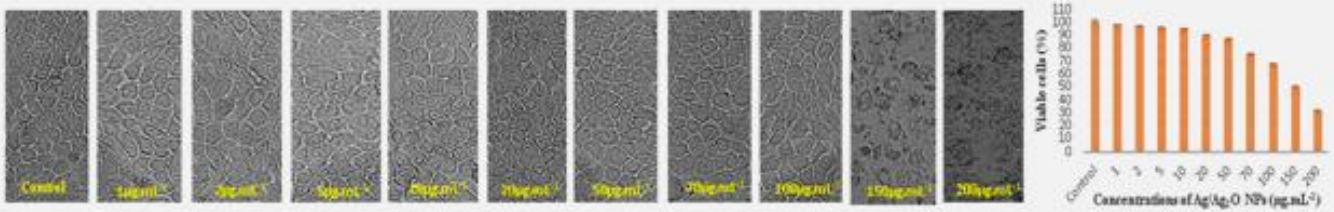

(c)
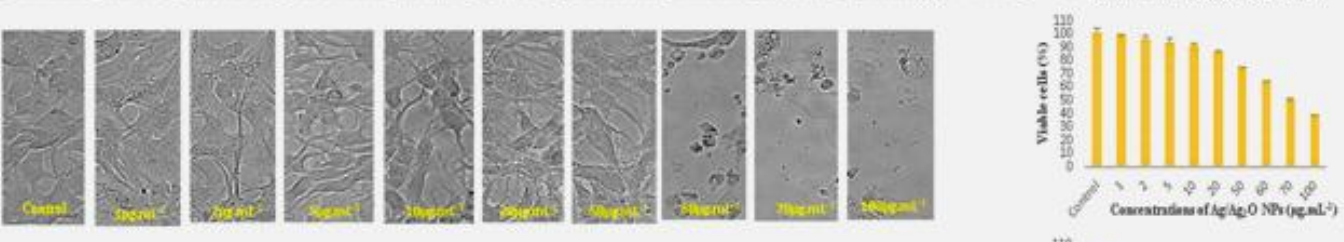

(d)
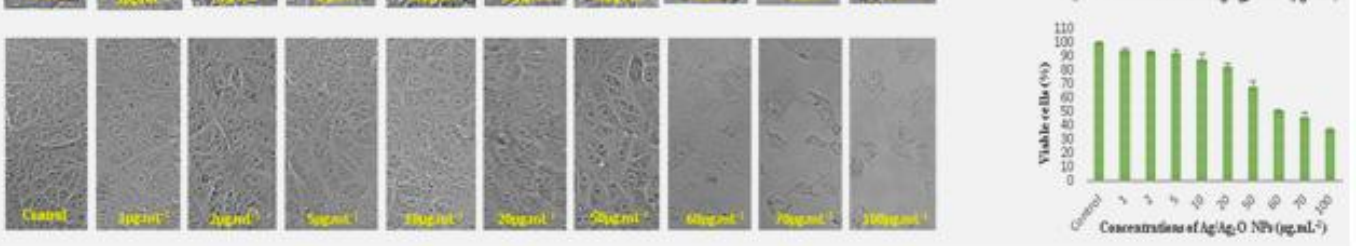

Figure6. Cytotoxicity assays of different concentrations of $\mathrm{Ag} / \mathrm{Ag}_{2} \mathrm{O} \mathrm{NPs}$ compared to untreated cells (Control), $200 X$ magnification, and evaluated in cells viability tests through AB assays, plotted in graphics beside of the cell panels. (a) BeWo cells; (b) A-253 cells; (c) KNS-42 cells and (d) Vero cells.

\section{CONClusions}

This study provides evidence that $\mathrm{Ag} / \mathrm{Ag} 2 \mathrm{O}$ NPs synthesized by a natural route (dead yeast biomass) could compete with other biogenic silver NPs and commercial antibiotics indicated for the treatment of infections. Thus, in addition to being derived from the recycling of metal pollutants, assisting in the cleaning of ecossystem, these NPs may also be used as efficient antimicrobial agents to combat infections caused by multidrug-resistant pathogenic microorganisms. However, further studies are needed to elucidate the exact mechanism of action of $\mathrm{Ag} / \mathrm{Ag} 2 \mathrm{O}$ NPs on microorganisms, and in vivo experiments in animal models before their use as antimicrobial agents.

\section{REFERENCES}

[1] Gajbhiye M., Kesharwani J., Ingle A., Gade A. and Rai. M., Fungus-mediated synthesis of silver nanoparticles and their activity agains pathogenic fungi in combination with fluconazole, Nanomed. Nanotech. Biol. Med. 5, 382 (2009).

[2] Kim J.S., Kuk E.K., Yu N.J., Kim H., Park S.J., Lee H.J., Kim S.H., Park Y.K., Park Y.H., Hwang C.Y., Kim Y.K., Lee Y.S., Jeong D.H. and Cho. M.H., Antimicrobial effects of silver nanoparticles, Nanomed. Nanotech. Biol. Med. 3, 95 (2007).

[3] Saha S., Chattopadhyay D. and Acharya. K., Preparation of silver nanoparticles by bioreduction using Nigrospora oryzae culture filtrate and its antimicrobial activity, Dig. J. Nanomater. Biostruct. 6, 1519 (2011). 
[4] Kumar P., Selvi S.S., Prabha A.L., Kumar K.P., Ganeshkumar R.S. and Govindaraju M., Synthesis of silver nanoparticles from Sargassum tenerrimum and screening phytochemicals for its antibacterial activity, Nanobiomed. Eng. 4, 12 (2012).

[5] Maiti S., Krishnan D., Barman G., Ghosh S.K. and Laha J.K., Antimicrobial activies of silver nanoparticles synthesized from Lycopersicon esculentum extract, JAST. 5, 1 (2014).

[6] Salvadori M.R., Ando R.A., Nascimento C.A.O. and Corrêa B., J. Dead biomass of Amazon yeast: A new insight into bioremediation and recovery of silver by intracellular synthesis of nanoparticles. Environ. Sci. Health Part A. 52, 1112 (2017).

[7] Velazquez-Meza M.E., Staphylococcus aureus methicillin-resistant: Emergence and dissemination, Salud Publica Mex. 47, 381 (2005).

[8] Earnshaw J.J., Methicilin-resistant Staphylococcus aureus: Vascular surgeons should fight back, J. Vasc. Endovasc. Surg. 4, 283 (2002).

[9] Magiorakos A.P., Srinivasan A.R., Carey B., Carmeli Y., Falagas M.E., Giske C.G., Harbarth S., Hindler J.F., Kahlmeter G., Olsson-Liljequist B., Paterson D.L., Rice L., Stelling B.J., Struelens M.J., Vatopoulos A.J., Weber T. and Monnet D.L., Multidrug-resistant, extensively drug-resistant and pandrug-resistant bacteria: An international expert proposal for interim standard definitions for acquired resistance, Clin. Microbiol. Infect. 18, 268 (2012).

[10] Sloan D.J. and Parris V., Cryptococcal meningitis: epidemiology and therapeutic options, Clin. Epidemiol. 6, 169 (2014).

[11] Franzot S.P., Salkin I.F. and Casadevall A., Cryptococcus neoformans var. grubii: separate varietal status for Cryptococcus neoformans serotype A isolates, J. Clin. Microbiol. 37, 838 (1999).

[12] Skladanowski M, Golinska P, Rudnicka K, Dahm H. and Rai M., Evaluation of cytotoxicity, immune compatibility and antibacterial activity of biogenic silver nanoparticles, Med. Microbiol. Immunol. 205, 603 (2016).

[13] Salvadori M.R., Ando R.A., do Nascimento C.A.O. and Corrêa B., Intracellular biosynthesis and removal of copper nanoparticles by dead biomass of yeast isolated from the wastewater of a mine in the Brazilian Amazonia, Plos One. 9, 1 (2014).

[14] Salvadori M.R., Ando R.A., Muraca D., Knobel M., Nascimento C.A.O. and Corrêa B., Magnetic nanoparticles of $\mathrm{Ni} / \mathrm{NiO}$ nanostructured in film form synthesized by dead organic matrix of yeast, RSC Adv. 6, 60683 (2016).

[15] Andrews J.M., Determination of minimum inhibitory concentrations, J. Antimicrob. Chemother. 48, Suppl 1,5 (2001).

[16] Ruparelia J. Chatterjee A., Duttagupta S. and Mukherji S., Strain specificity in antimicrobial activity of silver and copper nanoparticles, Acta Biomater. 4, 707 (2008).

[17] Salvadori M.R., Yamada A.T. and Yano T., Morphological and intracellular alterations induced by cytotoxin VT2y produced by Escherichia coli isolated from chickens with swollen head syndrome, FEMS Microbiol. Lett. 197, 79 (2001).

[18] Ravindran A., Chandran P. and Khan S.S. Biofunctionalized silver nanoparticles: advances and prospects, Colloids Surf B: Biointerfaces. 105, 342 (2013).

[19] Suresh S., Karthikeyam S., Saravanan P. and Jayamoorthy K., Comparison of antibacterial and antifungal activities of 5-amino-2-mercaptobenzimidazole and functionalized $\mathrm{NiO}$ nanoparticles. Karbala Inter. J. Modern. Sci. 2, 188 (2016).

[20] Sondi I. and Salopek-Sondi B., Silver nanoparticles as antimicrobial agente: A case study on E. coli as a model for gram-negative bacteria, J. Colloid. Interface Sci. 275, 177 (2004).

[21] Banerjee M, Mallick S., Paul A., Chattopadhyay A. and Ghosh S.S., Heightened reactive oxygen species generation in the antimicrobial activity of a three component iodinated chitosan? Silver nanoparticle composite, Langmuir. 26, 5901 (2010).

[22] Pal S., Tak Y.K. and Song J.M., Does the antibacterial activity of silver nanoparticles depend on the shape of the nanoparticle? A study of the gram-negative bacterium Escherichia coli, Appl. Environ. Microbiol. 73,1712 (2007). 
[23] Travan A., Pelillo C., Donati I., Marsich E., Benincasa M., Scarpa T., Semeraro S., Turco, G., Gennaro R. and Paoletti S., Non-cytotoxic silver nanoparticle-polysaccharide nanocomposites with antimicrobial activity, Biomacromolecules. 10, 1429 (2009).

[24] Qian Y., Yu H., He D., Yang H., Wang W., Wan X. and Wang L., Biosynthesis of silver nanoparticles by the endophytic fungus Epicoccum nigrum and their activity against pathogenic fungi, Bioprocess Biosyst. Eng. 36, 1613 (2013).

[25] Xu Y., Gal C., Li X., He Y., Zhou L., Pang G. and Sun S., In vitro antifungal activity of silver nanoparticles against ocular pathogenic filamentous fungi, J. Ocu. Pharmacol. Ther. 29, 270 (2013).

[26] Barua S., Konwarh R., Bhattacharya S.S., Das P., Devi K.S., Maiti T.K., Mandal M. and Karak N., Nonhazardous anticancerous and antibacterial colloidal "green" silver nanoparticles, Colloids Surf. B Biointerfaces. 105, 37 (2013).

Citation: Marcia Regina Salvadori, et al. "Antimicrobial Activity of Ag/Ag2O Nanoparticles Synthesized by Dead Biomass of Yeast and their Biocompatibility with Mammalian Cell Lines", International Journal of Research Studies in Microbiology and Biotechnology (IJRSMB), vol. 5, no. 1, pp. 7-15, 2019. Available: DOI: http://dx.doi.org/10.20431/2454-9428.0501002

Copyright: (C) 2019 Authors. This is an open-access article distributed under the terms of the Creative Commons Attribution License, which permits unrestricted use, distribution, and reproduction in any medium, provided the original author and source are credited. 